\title{
Single-Phase Shunt Active Filter Interfacing Renewable Energy Sources with the Power Grid
}

\author{
Pedro Neves, D. Gonçalves, J. G. Pinto, Renato Alves, João L. Afonso \\ Industrial Electronics Department, University of Minho, Guimarães, Portugal \\ Email: \{pneves|dgoncalves|gpinto|ralves|jla\}@dei.uminho.pt
}

\begin{abstract}
This paper presents a single-phase Shunt Active Filter combined with a Maximum Power Point Tracker (MPPT) connected to a solar panel array. The Shunt Active Filter's power stage consists of a two-leg IGBT inverter commanded by a Digital Signal Processor (DSP) with control based on the Theory of Instantaneous Reactive Power (p-q Theory). The MPPT is based on a step-up circuit commanded by a DSP with MPPT Algorithm implemented. The output of the MPPT circuit is connected to the DC side of the Shunt Active Filter. The system is capable of compensating power factor and current harmonics, and at the same time, using the same inverter, injecting in the power grid electric energy produced by solar panels, regulated by the MPPT. There will be presented results of the system operating in an electrical installation under different conditions, as well as the hardware configuration and specifications.
\end{abstract}

\section{INTRODUCTION}

Due to the intensive use of non linear loads, such as power converters and others, there is an increasing number of power quality problems in the electrical systems. Problems like harmonics, inter-harmonics, flicker, notches, sags, swells and others can cause malfunction to equipments based on microelectronic circuits that are very sensible to disturbances in the power supply. In order to minimize the impact of these power quality problems, in 1976 Gyugi and Strycula introduced the concepts of active filters [1].

Active filters, different from the passive ones, have the capability of dynamically adjusting to the conditions of the system in terms of harmonics and reactive power compensation. The Shunt Active Filter drains from the grid the distorted components of the load currents in a way that the system currents become with small harmonic distortion and in phase with the system voltages. Problems like the ones described above have a greater impact in the industrial environment, but in domestic and commercial use most loads are non linear as well, causing disturbances to the electrical system and to more sensitive loads.

As the need for distributed power production increases, low power renewable energy production systems, like solar systems become more used, especially in Portugal with favorable through the year conditions of sun. To maintain power quality in the distribution, the energy should be injected as a sinewave and with the appropriate power factor as proposed by the system described in this paper.

A diagram block of the system is displayed in Fig. 1. The solar panels (connected in series) are connected to the MPPT,

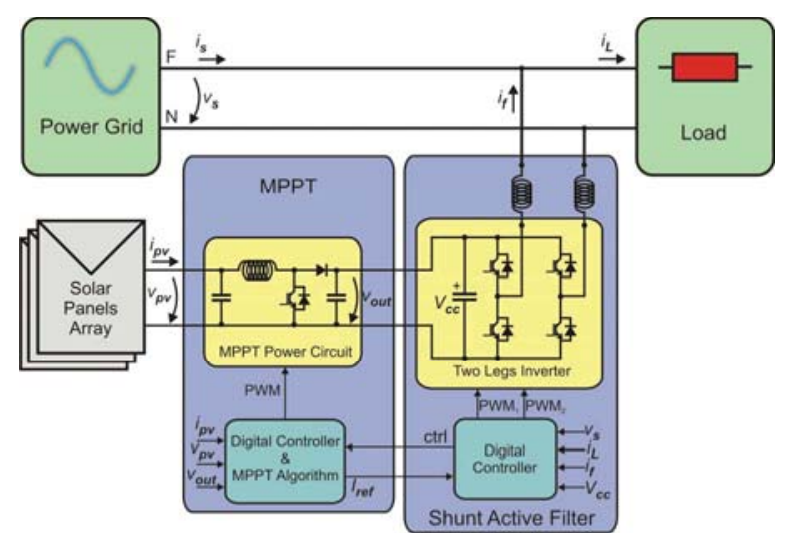

Fig. 1. Block Diagram of the system

which steps up the voltage and connects its secondary side to the DC side of the Shunt Active Filter which is connected directly to the power grid through coupling inductors.

The Shunt Active Filter, combined with the MPPT is capable of mitigating current harmonics and power factor and, simultaneously, injecting energy produced by renewable sources in the power grid [2].

The system is composed by a solar panel array of 16 solar panels. Each solar panel has a nominal power of $200 \mathrm{~W}$, an open circuit voltage $\left(\mathrm{V}_{\mathrm{OC}}\right)$ of $32,9 \mathrm{~V}$ and a short-circuit current $\left(\mathrm{I}_{\mathrm{CC}}\right)$ of $8,21 \mathrm{~A}$. The solar panels are connected in series making a total $\mathrm{V}_{\mathrm{OC}}$ of $526,4 \mathrm{~V}$. The series connected solar array is connected to the input of the MPPT circuit, which is a typical DC-DC converter controlled by a DSP. The DSP reads values of input voltage, input current and output voltage and calculates the maximum power available from the solar panels. It also determinates the duty-cycle applied to the power switch setting the output voltage desired. The DSP responsible for controlling the MPPT also communicates with the DSP of the Shunt Active Filter to let it know how much power is available from the solar panels to inject in the power grid.

In this paper there will be presented results of the described system working in an electrical installation where the loads are mainly computers, screens, printers and lighting. These loads cause considerable harmonic distortion to the current, as well as power factor, which makes the job of the Shunt Active Filter important. Also, these loads are changing very frequently, mainly because of printers, so there will be shown waveshapes acquired when the power produced by the solar panels is higher than the power being consumed by the loads, and otherwise, when the loads consume more power than the amount being produced by the solar panels. 


\section{Shunt Active Filter}

\section{Shunt Active Filter Controller}

In 1983, Akagi et al. [3, 4] proposed "The Generalized Theory of the Instantaneous Reactive Power in Three-Phase Circuits", also known as "Theory of Instantaneous Reactive Power" , or p-q Theory. It was initially developed for threephase three-wire systems, with a brief mention to systems with neutral wire. Later, Watanabe et al. [5] and Aredes et al. [6] extended it to three-phase four-wire systems. This theory is based on instantaneous values in three-phase power systems with or without neutral wire, and is valid for steadystate or transitory operation. The $\mathrm{p}-\mathrm{q}$ theory consists of an algebraic transformation (Clarke transformation) of the threephase voltages and currents in the a-b-c coordinates to the $\alpha$ $\beta-0$ coordinates according to the expression (1), where $\mathrm{x}$ can be voltages (v) or currents (i).

$$
\left[\begin{array}{l}
x_{0} \\
x_{\alpha} \\
x_{\beta}
\end{array}\right]=\sqrt{2} / 3 \cdot\left[\begin{array}{ccc}
1 / \sqrt{2} & 1 / \sqrt{2} & 1 / \sqrt{2} \\
1 & -1 / 2 & -1 / 2 \\
0 & \sqrt{3} / 2 & -\sqrt{3} / 2
\end{array}\right] \cdot\left[\begin{array}{l}
x_{a} \\
x_{b} \\
x_{c}
\end{array}\right]
$$

After the transformation, the $\mathrm{p}-\mathrm{q}$ theory components are calculated using the expressions (2-4), where $p$ is the instantaneous real power, $q$ is the instantaneous imaginary power (by definition) and $p 0$ is the instantaneous zero sequence power.

$$
\begin{aligned}
& p=v_{\alpha} \cdot i_{\alpha}+v_{\beta} \cdot i_{\beta} \\
& q=v_{\beta} \cdot i_{\alpha}-v_{\alpha} \cdot i_{\beta} \\
& p_{0}=v_{0} \cdot i_{0}
\end{aligned}
$$

Normally, only the average value of the instantaneous real power $(p)$ is desirable and the other power components can be compensated using a Shunt Active Filter. In order to calculate the reference currents that the active filter should inject it is necessary to separate the desired components from the undesired ones. The undesired components, $p x$ and $q x$, are used to determinate the compensation currents in the $\alpha-\beta-0$ coordinates by the expressions $(5,6)$.

$$
\begin{aligned}
& {\left[\begin{array}{l}
i_{c \alpha} \\
i_{c \beta}
\end{array}\right]=\frac{1}{v_{\alpha}^{2}+v_{\beta}^{2}} \cdot\left[\begin{array}{cc}
v_{\alpha} & v_{\beta} \\
-v_{\beta} & v_{\alpha}
\end{array}\right] \cdot\left[\begin{array}{c}
p_{x} \\
q_{x}
\end{array}\right]} \\
& i_{c 0}=i_{0}=\frac{1}{\sqrt{3}} \cdot\left(i_{a}+i_{b}+i_{c}\right)
\end{aligned}
$$

The compensation currents in the a-b-c coordinates are determined by applying the inverse Clarke transformation to the currents in the $\alpha-\beta-0$ coordinates, as demonstrated in (7).

$$
\left[\begin{array}{l}
i_{c a} \\
i_{c b} \\
i_{c c}
\end{array}\right]=\sqrt{2 / 3} \cdot\left[\begin{array}{ccc}
1 / \sqrt{2} & 1 & 0 \\
1 / \sqrt{2} & -1 / 2 & \sqrt{3} / 2 \\
1 / \sqrt{2} & -1 / 2 & -\sqrt{3} / 2
\end{array}\right] \cdot\left[\begin{array}{c}
i_{c 0} \\
i_{c \alpha} \\
i_{c \beta}
\end{array}\right]
$$

The original p-q Theory is only applicable to three-phase systems. To apply this theory to single-phase systems [7] it was created two virtual currents and two virtual voltages with the same amplitude as the measured current and voltage but shifted $\pm 120^{\circ}$ to perform a virtual, balanced, three-phase system. After this operation the methodology is the same as applied in real three-phase systems. At the end of the calculations only one of the three reference currents is used to control the inverter. The virtual voltages and currents were created using arrays in the digital control system, that was implemented on a Texas Instruments TMS320F2812 DSP.

In addition to the instantaneous power components defined by the p-q Theory, there is also a component, preg, which is used to regulate the capacitor voltage in the DC side of the Shunt Active Filter. This regulation is done with a proportional controller and the error between the reference voltage $\left(V_{r e f}\right)$ and the voltage measured at the DC side of the inverter $\left(V_{D C}\right)$. The component preg is included in the value of $p x$ and calculated as shown in (8).

$$
p_{\text {reg }}=k_{p}\left(V_{\text {ref }}-V_{D C}\right)
$$

\section{Shunt Active Filter Hardware}

The power circuit of the single-phase Shunt Active Filter is constituted by a two-leg, 4 IGBTs (with antiparallel diodes), Voltage Source Inverter (VSI). The DC side of the inverter uses two capacitors in series (with $4.7 \mathrm{mF}$ capacitance each). Between the inverter and the points of connection to the electric grid it is used two different air core inductors. In the phase wire it is used a $2,16 \mathrm{mH}$ inductor to decrease the ripple of the compensating current produced by the Shunt Active Filter and in the neutral wire it is used a $695 \mu \mathrm{H}$ inductor to reduce noise in the control system.

The measured signals necessary to the control system were obtained with voltage and current Hall effect sensors. In Fig. 1 it is possible to identify these signals as AC system voltage $\left(v_{s}\right)$, inverter DC side voltage $\left(V_{D C}\right)$, load current $\left(i_{L}\right)$, and active filter current $\left(i_{F}\right)$.

The Shunt Active Filter is equipped with an autonomous controller based on an independent microcontroller that manages start and end sequences of operation. During normal operation, the supervision system manages error detection and protections such as overtemperature, overcurrent and overvoltage in the DC side. The Shunt Active Filter described in this paper was also equipped with an Electric Power Quality Monitor [8]. 


\section{MPPT}

The MPPT $\mathrm{s}$ function is to maximize the power produced by the panels by controlling the optimum point of voltage and current in which the solar panels operate. This is done by monitoring the voltage $\left(v_{p v}\right)$ and current $\left(i_{p v}\right)$ of the solar panels array and, regarding its behavior, extract more or less power. This power extraction control is necessary because the solar panels operate with non linear Voltage Current (V I) curve which changes with incident solar radiation and panel temperature. The MPPT communicates with the Shunt Active Filter so that it knows how much power is available from the panels to inject in the power grid.

\section{Controller}

Fig. 2 shows the sequence of operation of the MPPT controller, which includes an initialization process that consists on connecting the solar panels array to the DC-DC converter, and connecting the converter to the Shunt Active Filter after $V_{\text {out }}$ pre-charge.

There are two main functions performed by the MPPT algorithm. The first of these functions is to control the output voltage of the DC-DC converter, regulating the PWM dutycycle applied to the switch of the MPPT power circuit. The "Regulate $V_{\text {out }}$ " function uses a closed-loop proportional controller to minimize the error of the output voltage $\left(V_{\text {out }}\right)$. The second function of the MPPT controller is to perform the MPPT algorithm. There are about twenty different types of MPPT algorithms which differ in number and kind of input variables and in response speed and efficiency [9]. The types most used are Perturb bserve $(\mathrm{P} \quad)$ and Incremental Conductance (InC) algorithms, being the $(\mathrm{P} \quad$ ) the most used between both because of its simplicity and good efficiency in most operation conditions. The $\mathrm{P}$ has the drawback of having a poor response to rapid solar radiation change. $\mathrm{n}$ the other hand, the $\mathrm{InC}$ algorithm has a good response to rapid solar radiation change but needs more computational effort [10].

In the application presented in this paper it was used the $\mathrm{P} \quad$ MPPT algorithm. It uses two input variables $v_{p v}$ and $i_{p v}$ to observe variations of power when a perturbation is applied and this way seek for the Maximum Power Point. Usually, the perturbation variable is the voltage, however the variable used in this P algorithm is the current $\left({ }_{r e f}\right)$ since the output voltage must be fixed. In essence, the $\mathrm{P}$ algorithm consists in perturbing ref and observing its effect on the power of the solar panels $\left({ }_{p v}\right)$. If the power increases, the direction of the perturbation is maintained. If the power decreases, the direction of the perturbation is inverted as shown in Fig. 3. These decisions are taken only if a minimum amount of power ( 1 ) and a minimum amount of current ( 2) has changed in order to avoid that noise caused by switching origins a decision in control. The perturbation amplitude is represented by $C 1$ when increased and $C 2$ when decreased. In each iteration, the calculated value of $r e f$ is sent to the Shunt Active Filter so that it performs a perturbation.

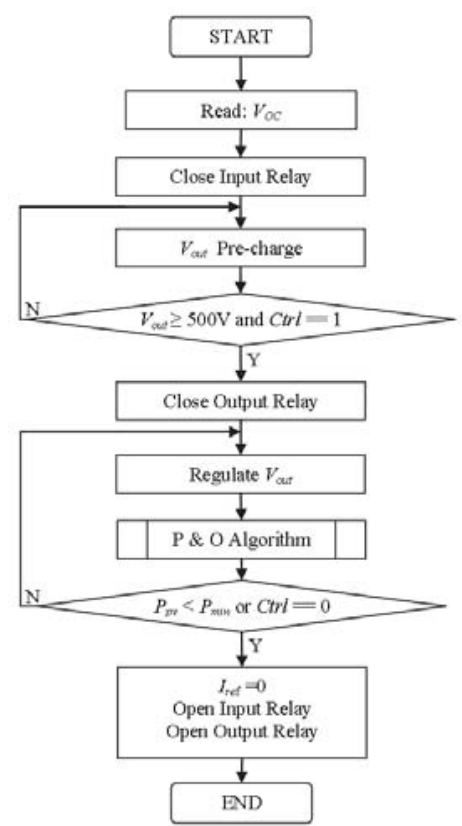

Fig. 2. MPPT controller main flowchart

\section{Hardware}

The DC-DC step-up converter circuit regulates the voltage at the output $\left(V_{\text {out }}\right)$ to about $500 \mathrm{~V}$. To meet this value, the solar panel array was sized to have a maximum operation voltage just under $500 \mathrm{~V}$. This way, the step-up converter configuration is appropriate for this application since it will operate with a low duty-cycle value allowing the converter to operate with small power losses.

The converter uses a Polypropylene input capacitor $\left(\mathrm{C}_{\text {in }}\right)$ of $40 \mu \mathrm{F}$ with the purpose of reducing the input voltage $\left(v_{p v}\right)$ ripple. In the output of the converter it uses a similar capacitor. The converter circuit also uses a $5 \mathrm{mH}$, air core inductor and as active components it was used an IGBT switch and a fast recovery diode.

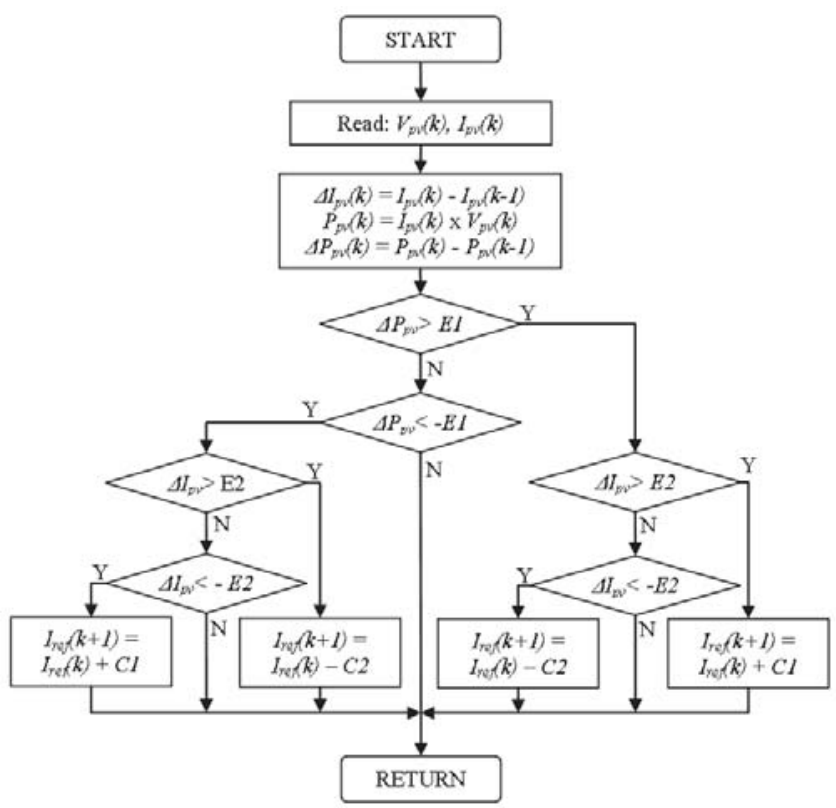

Fig. 3. P algorithm flowchart implemented 


\section{Shunt Active Filter Plus MPPT}

The Shunt Active Filter and the MPPT work in cooperation. When the Shunt Active Filter is put into operation, it informs the MPPT controller to begin its operation through Ctrl flag (flowchart in Fig. 2). nce operating, the perturbation variable calculated by the MPPT $(r e f)$ is transmitted to the Shunt Active Filter so that it injects in the power grid the amount of power calculated.

This value is inputted in the calculations of the Shunt Active Filter [11] as an addition to the previously calculated preg value as described in (9) and (10).

$$
\begin{gathered}
p_{g}=k_{g} \times i_{r e f} \\
p_{r e g}=p_{r e g}+p_{g}
\end{gathered}
$$

\section{RESUlTS}

The results presented were acquired with the system operating in an electric board that feeds rooms of a computational center in University of Minho. The loads present in these rooms are mainly computers, screens, printers and lighting.

The electric board of the Shunt Active Filter is shown in Fig. 4. For measurement and viewing purposes, together with the Active Filter, it was installed an Electric Power Quality Monitor.

The results shown is this paper were obtained with the system operating in three distinct operating conditions In the first case the Shunt Active Filter is working alone compensating the current harmonics and power factor in the

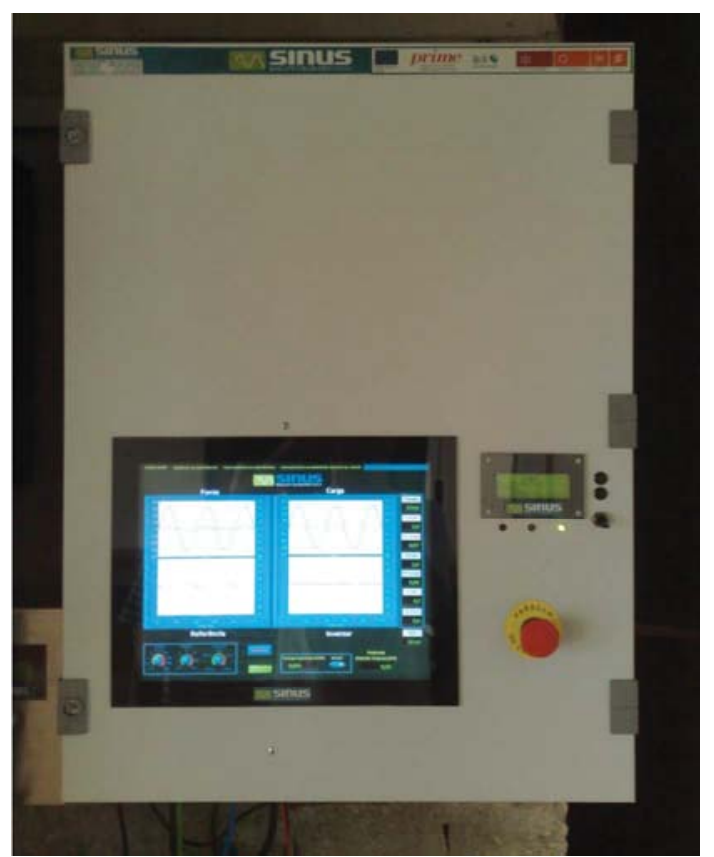

Fig. 4. Shunt Active Filter electric board installed in University of Minho second case, the whole system (Shunt Active Filter plus MPPT) is working, compensating current harmonics and power factor and injecting into the electric grid power being produced by the solar panels in about the same amount as the loads consumption, and in the third case it will be shown results of the system working, with the solar panels producing more power than the amount being consumed by the loads which makes the source current 180 degrees out of phase from the system voltage.

The results were performed in a $230 \mathrm{~V} 50 \mathrm{~Hz}$ electrical system and the waveshapes are presented with a voltage scale of $100 \mathrm{~V}$ div and a current scale of $10 \mathrm{~A}$ div.

The waveshapes were acquired using a okogawa DL708E oscilloscope. The THD and Power factor values were obtained using the Electric Power Quality Monitor installed with the Active Filter.

In each case presented, it was taken two sets of waveshapes one with the system voltage and source current and another with system voltage and load current. This way it can be made a comparison between what is being supplied by the power system and what is being consumed by the loads.

In the first case, shown in Fig. 5, the Shunt Active Filter is compensating a load that causes reactive power and harmonic distortion. Because of the Shunt Active Filter, the source current is in phase with the system voltage and with a waveshape close to sinusoidal. Table I gives the values of current amplitude, current Total Harmonic Distortion (THD) and Power Factor in the source as well as in the load in the situation where Fig. 5 was acquired. By these results, it can be seen that the current amplitude has decreased as harmonic content has lowered and as Power Factor became unitary. The current THD decreases from 15,6 to 3,5 and the Power Factor goes from 0,90 to 1,00 .

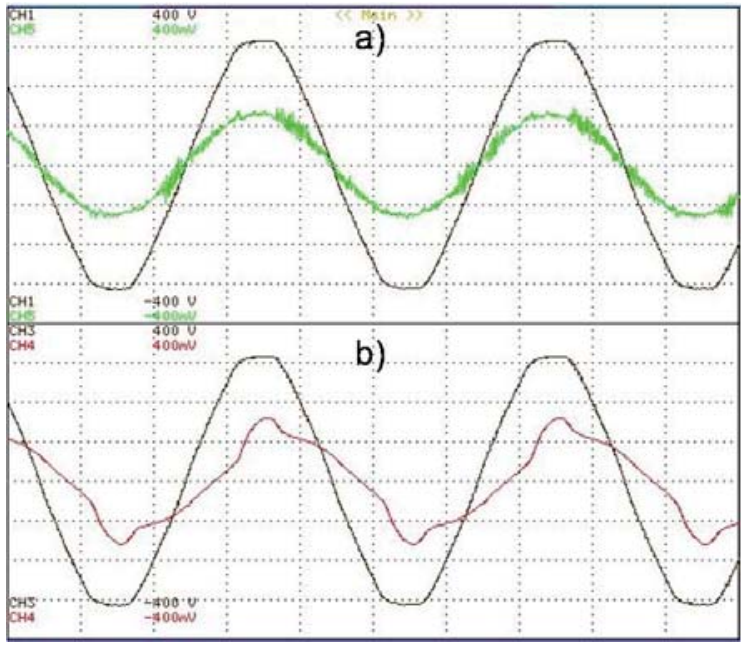

Fig. 5. First case a) System voltage and source current b) System voltage and load current

TABLE I

PERF RMANCE F THE S STEM IN FIg. 2 SituAti N

\begin{tabular}{|l|c|c|c|}
\hline & Current & Current THD & Power Factor \\
\hline Source & $9,2 \mathrm{~A}$ & 3,5 & 1,00 \\
\hline Load & $9,7 \mathrm{~A}$ & 15,6 & 0,90 \\
\hline
\end{tabular}


The MPPT was installed next to the Shunt Active Filter electric board, as shown in Fig. 7, with two wires connecting the DC side of the two circuits and two wires for communications so that the MPPT controller lets the Shunt Active Filter know how much power is available from the solar panels to be injected in the power grid. The solar panels were installed in a roof top close to the electric board, with fixed orientation turned to south with a 30 degrees inclination angle from the horizontal as shown in Fig. 8.

In Fig. 6, it can be seen that the load is the same as in Fig. 5. However, in this case, the MPPT is operating, making the Shunt Active Filter able to inject in the power grid, energy produced by the solar panels. It can be observed by the source current in Fig. 6 that the amount of power being consumed by the loads and the amount of power being produced by the solar panels is very similar making the current in the source almost null. In Table II it can be noticed that, even though the load is consuming 9,7 A, the current in the source is only 0,5 A. Also, the Power Factor improves from 0,90 to 0,99 and the current THD improves from 15,6 to 9,9 with very low amplitude.

Fig. 9 shows an example where the current is smaller than in the previous cases and with much higher harmonic content. In this case, the power being produced by the solar panels is higher than the power being consumed by the loads. It is possible to notice that the current in the source is inverted (180 degrees out of phase) from the system voltage. The values in Table III shows that the Power Factor in the load is 0,86 and the current THD is 53,9 . With the Shunt Active Filter operating, in the source, the Power Factor becomes unitary, the current THD decreases to 6,1 and the current amplitude goes from 3,6 A being spent to 6,5 $\mathrm{A}$ being injected in the power grid.

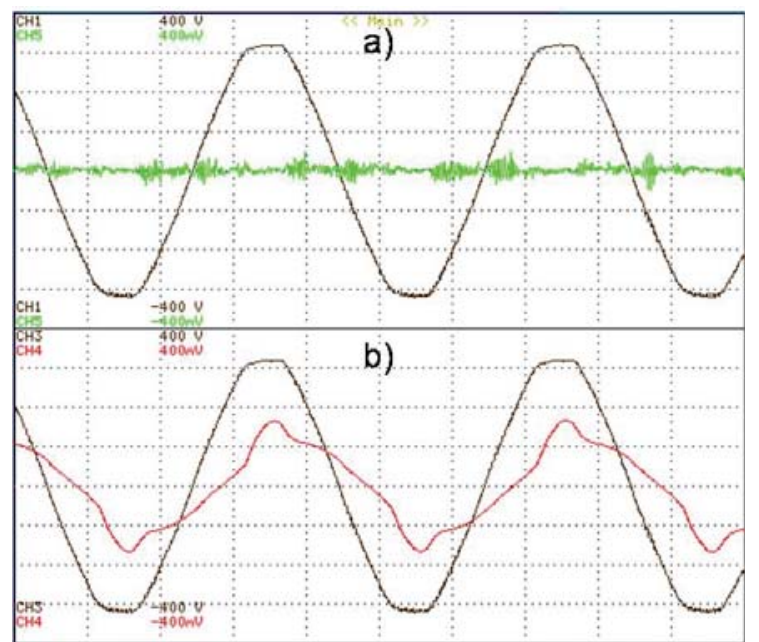

Fig. 6. Second case a) System voltage and source current b) System voltage and load current

TABLE II

PERF RMANCE F THE S STEM IN FIg. 3 SITUATI N

\begin{tabular}{|l|c|c|c|}
\hline & Current & Current THD & Power Factor \\
\hline Source & $0,5 \mathrm{~A}$ & 9,9 & 0,99 \\
\hline Load & $9,7 \mathrm{~A}$ & 15,6 & 0,90 \\
\hline
\end{tabular}

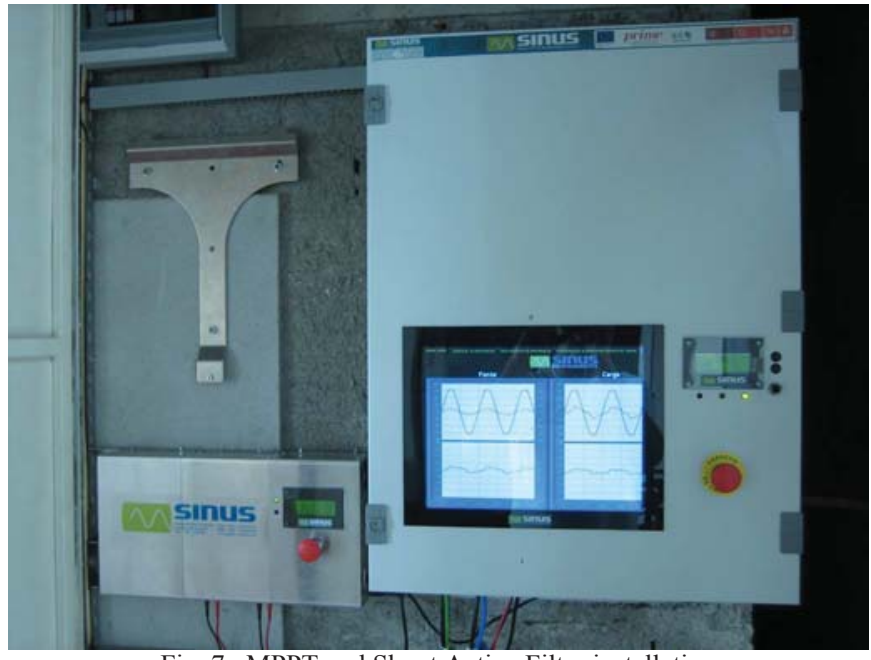

Fig. 7. MPPT and Shunt Active Filter installation

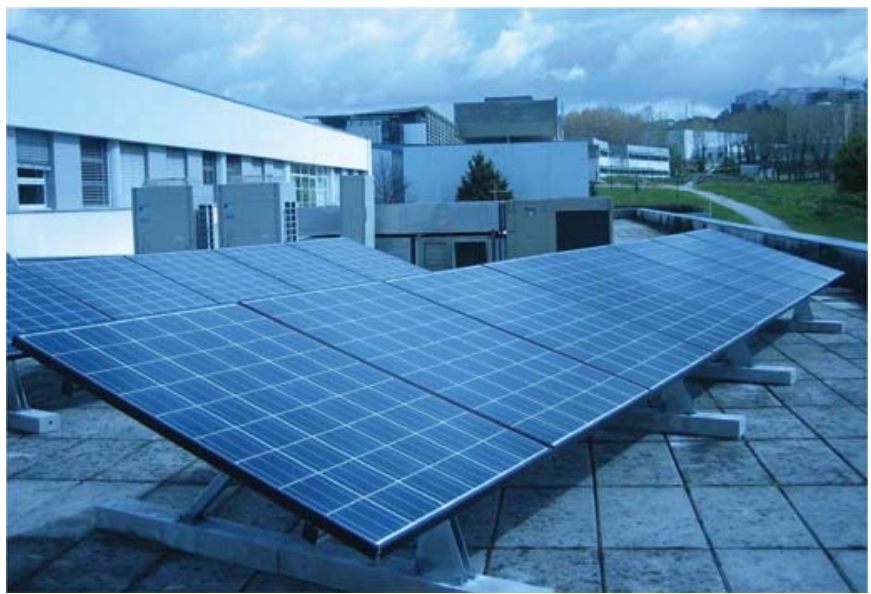

Fig. 8. Solar panel array installation

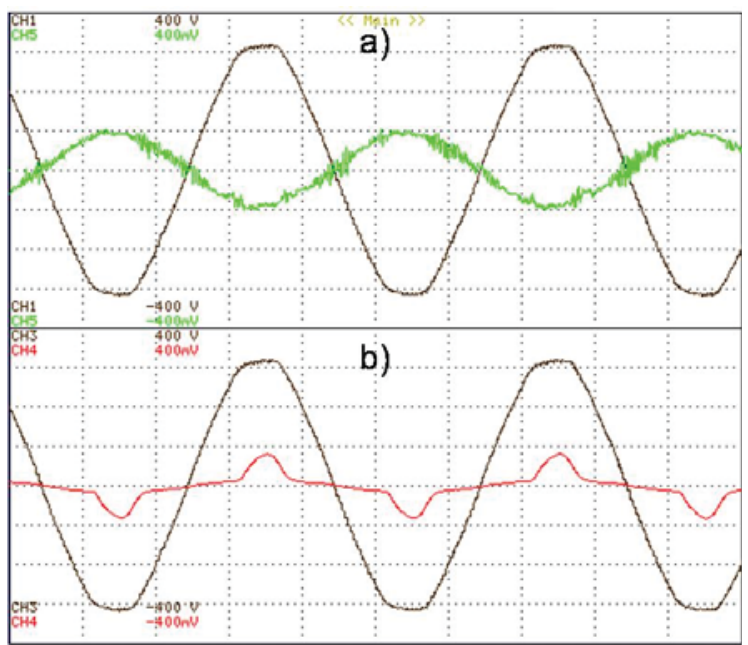

Fig. 9. Third case a) System voltage and source current b) System voltage and load current

TABLE III

PERF RMANCE F THE S STEM IN FIG. 4 SITUATI N

\begin{tabular}{|l|c|c|c|}
\hline & Current & Current THD & Power Factor \\
\hline Source & $-6,5 \mathrm{~A}$ & 6,1 & 1,00 \\
\hline Load & $3,6 \mathrm{~A}$ & 53,9 & 0,86 \\
\hline
\end{tabular}




\section{C NCLUSI NS}

This paper presented experimental results of a single-phase Shunt Active Filter combined with a MPPT, injecting energy in the electric grid produced by a solar panel array. The results show the performance of the Shunt Active Filter operating alone, and also the complete system behavior in compensation and energy injection tasks simultaneously.

The presented configuration shows some advantages over the traditional ones since it gathers functionalities of different equipments using the same hardware to accomplish the different tasks. The only drawback of the presented configuration is that the power inverter has to be increased because the injected current is composed by two components a component that represents the renewable energy to inject in the electric grid and a component to compensate harmonics and power factor of the facility.

The presented Active Power Filters are currently in industrialization process by the company EFACEC SGPS S.A.

\section{AC $\mathrm{N}$ WLEDGMENT}

This work was supported by the FCT (Funda o para a Ci ncia e Tecnologia), project funding P CTI ESE 411702001 and P CTI ESE 48242 2002. The authors are also grateful to PRIME (Programa de Incentivos Moderniza o da Economia) for funding the Project SINUS. Moderniza o da Economia)

\section{REFERENCES}

[1] L. Gyugi and E. C. Strycula, "Active AC Power Filters", IEEE-IAS Annual Meeting Record, 1976, pp. 529-535.
[2] . G. Pinto, R. Pregitzer, Lu s F. C. Monteiro, o o L. Afonso, "3 Phase 4 Wire Shunt Active Power Filter with Renewable Energy Interface", Proceedings of ICREPQ 07- International Conference on Renewable Energies and Power Quality, 28-30 March 2007, Seville, Spain, ISBN 978-84-611-4707-6.

[3] H. Akagi, . anazawa, A. Nabae, "Generalized Theory of the Instantaneous Reactive Power in Three-Phase Circuits", IPEC 83 - Int. Power Electronics Conf., Tokyo, apan, 1983, pp. 1375-1386.

[4] H. Akagi, . anazawa, A. Nabae, "Instantaneous Reactive Power Compensator Comprising Switching Devices without Energy Storage Components", IEEE Trans. Industry Applic., vol. 20, May une 1984.

[5] E. H. Watanabe, R. M. Stephan, M. Aredes, "New Concepts of Instantaneous Active and Reactive Powers in Electrical Systems with Generic Loads", IEEE Trans. Power Delivery, vol. 8, no. 2, April 1993, pp. 697-703.

[6] M. Aredes, E. H. Watanabe, "New Control Algorithms for Series and Shunt Three-Phase Four-Wire Active Power Filters", IEEE Trans. Power Delivery, vol 10, no. 3, uly 1995, pp. 1649-1656.

[7] Pedro Neves, Gabriel Pinto, Ricardo Pregitzer, Lu s Monteiro, o o L. Afonso, "Experimental Results of a Single-Phase Shunt Active Filter Prototype with Different Switching Techniques", Proceedings of ISIE 2007- 2007 IEEE International Symposium on Industrial Electronics, 47 une 2007, Vigo, Spain, ISBN 1-4244-0755-9.

[8] os Batista, lio S. Martins, o o L. Afonso, "Low-Cost Power Quality Monitor Based on a PC", ISIE 2003 - IEEE International Symposium on Industrial Electronics, Rio de aneiro, Brasil, 9-11 unho de 2003, ISBN 0-7803-7912-8.

[9] Esram, T. Chapman, "Comparison of Photovoltaic Array Maximum Power Point Tracking Techniques", P.L. Energy Conversion IEEE Transaction on Volume 22, Issue 2, une 2007 Page(s) 439 - 449 Digital bject Identifier 10.1109 TEC.2006.874230.

[10] Hohm, D.P. Ropp, "Comparative study of maximum power point tracking algorithms using an experimental, programmable, maximum power point tracking test bed", M.E. Photovoltaic Specialists Conference, 2000. Conference Record of the Twenty-Eighth IEEE1522 Sept. 2000 Page(s) 1699 - 1702 Digital bject Identifier 10.1109 PVSC.2000.916230.

[11] L. G. B. Rolim, A. rtiz, M. Aredes, R. Pregitzer, . G. Pinto, o o L. Afonso, "Custom Power Interfaces for Renewable Energy Sources", Proceedings of ISIE 2007- 2007 IEEE International Symposium on Industrial Electronics, 4-7 une 2007, Vigo, Spain, ISBN 1-4244-0755-9. 